\title{
Condition of informal caregivers in long-term care of people with dementia
}

\author{
Roksana Malak', Agnieszka Krawczyk-Wasielewska', Katarzyna Głodowska², Bartosz Grobelny³, \\ Paweł Kleka ${ }^{4}$, Ewa Mojs ${ }^{3}$, Przemysław Keczmer' ${ }^{1}$, Włodzimierz Samborski ${ }^{1}$ \\ ${ }^{1}$ Department of Rheumatology and Rehabilitation, Poznan Univeristy of Medical Sciences, Orthopedic-Rehabilitation \\ Clinical Hospital in Poznan, Poland \\ ${ }^{2}$ Department of Social Sciences, Poznan University of Medical Sciences, Poland \\ ${ }^{3}$ Depertment of Clinical Psychology, Poznan Univeristy of Medical Science, Poland \\ ${ }^{4}$ Adam Mickiewicz University, Institute of Psychology, Poznan, Poland
}

Malak R, Krawczyk-Wasielewska A, Głodowska K, Grobelny B, Kleka P, Mojs E, Keczmer P, Samborski W. Condition of informal caregivers in long-term care of people with dementia. Ann Agric Environ Med. 2016; 23(3): 491-494. doi: 10.5604/12321966.1219193

\begin{abstract}
Introduction. Caregivers of demented relatives devote their time and attention in order to help the beloved members of the family. Those who are informal caregivers require support in order to avoid being overburdened. Many such caregivers may suffer from chronic health problems, for instance, depression.

Objective. The aim was to assess the factors of depression in caregivers, and to discover the determinants of depression among informal family caregivers of demented individuals.

Materials and method. Forty-one caregivers in the research group were administered a questionnaire which included the caregivers' demographics. Caregiver's level of depression was measured by the scale of the Centre for Epidemiology Scale for Depression. The relationship between depression and demographic features was analyzed. Data were analyzed using STATISTICA 8.1 (StatSoft). Analysis of the results was performed using the Kolmogorov-Smirnov test of normality. Pearson correlation coefficient was also used.

Results. Referring to The Centre for Epidemiology Scale for Depression, the average score in the study group was $18 \pm 7.49$. There was no statistically significant relationship between the level of depression and such factors as caregiver's age, time of care of demented relative, and type of kinship and pain.

Conclusions. Although there was no relationship between the level of depression and demographic features, the problem with quality of life, worries and grief which may appear, seemed to be sufficient reason for organizing the prevention of depression for all informal caregivers of persons with dementia.
\end{abstract}

\section{Key words}

depression, dementia, caregivers, psychiatry, family, pain

\section{INTRODUCTION}

People with dementia, a progressive neurodegenerative disorder [1], need long-term care. Although the symptoms are certainly heterogeneous, there are, however, some major groups of symptoms which are common to almost all those who suffer from dementia: problems with attention, memory, executive function, visual-spatial ability and language [2]. It is possible, but difficult, to provide appropriate long-term care for people with dementia, and it is especially difficult for an informal caregiver, such as member of the family of a demented person. This is primarily because dementia is a progressive illness, and sometimes a caregiver may not see effects of her or his work because of the relative developing a new stage of dementia. Additionally, the informal caregiver does not have to have medical knowledge about the disease and its typical symptoms which may be inconceivable in everyday life. The informal caregiver taking care of a demented relative is therefore exposed to caregiver burden. This is the reason that the burden of a caregiver has been the subject of growing interest worldwide [3].

Address for correspondence: Roksana Malak, Department of Rheumatology and Rehabilitation, Poznan Univeristy of Medical Sciences, Orthopedic-Rehabilitation Clinical Hospital in Poznań, 28 czerwca 1956 135/147, Poland

E-mail:rmalak@ump.edu.pl

Received: 19 November 2015; accepted: 11 April 2016
There are four main categories of symptoms characteristic for caregiver burden:

1) frequent mood swings - anger, sadness, irritability, discouragement, looking for magic solutions, inability to concentrate;

2) physical - posture failure (symptoms of fatigue), headaches, disturbed appetite and weight, sleeplessness, falling sick very often, neck pain, hyperhidrosis;

3) behavioral - problem in concentrating, increased use of drugs or alcohol, avoiding decisions, forgetfulness, boredom, over-reactiveness;

4) relationships - fewer contact with friends, loneliness, problems with marriage or children.

Anxiety and hostility could be other symptoms of caregiver burden [4]. Other factors may also increase caregiver burden, for instance, type of kinship of caregiver, gender of caregiver (female) may differ the symptoms of caregiver burden [4]. There are additionally some neuropsychological symptoms of caregiver burden, such as: delusions, hallucinations, restlessness, disinhibition, unusual motor behaviour, sleep disturbances and appetite alterations [5]. One of the most severe symptoms of burden is depression [4] which is associated with disturbance in the emotional, behavioural and social condition. Furthermore, caregivers who suffer from depression very often also report pain [6]. Depression may 
develop following a trigger symptom, such as the appearance of dementia in beloved member of family as a stressful and unhappy life event. Sleep disturbance, which may appear as a result of taking care of a demented relative, can also cause depressive symptoms. The importance of detecting and treating such depression should be highlighted. If a caregiver develops depression she or he will not be effective in taking care of the member of the family with dementia. It is therefore predictable that the longer the time of caregiving, the higher the probability of burden.

\section{OBJECTIVE}

The aim of the study was to assess the predictors of burden in caregivers and to discover the determinants of depression in family caregivers of demented individuals.The relationship between depression and demographic features was also analyzed.

\section{MATERIALS AND METHOD}

The necessary informed consent was obtained from all participants in the study which took place in 2014 . All caregivers in the study group were administered a questionnaire which included caregivers' demographics: age, gender, relationship with the patient, duration of the patient's disease, and time (hours per week spent with the patient). Caregiver level of depression was measured by The Centre for Epidemiology Scale for Depression (CES-D) was used to identify individuals had depressive symptoms and the level of depression. The respondents were asked to rate the frequency during the past week from among 18 depressive symptoms by choosing response options ranging from 'rarely or none of the time' to 'most or all of the time', on a scale ranging from $0-54$. The original recommended cut-off point for having depressive symptoms was 16 points (corresponding to the 80th centiles) by the founder of the CES-D in 1977 [7].

A sample of 41 members of families with a demented relative were interviewed to determine the influence of such factors as: finished graduation, caregiver's age, family relationship to the care recipient, leisure time, and having the support of other family members, to discover the impact of the appearance the depression. There were 32 spouses, 8 people who were single, and one divorced person. The majority of respondents had finished secondary education (22\%), higher education (39\%), vocational education (5\%), and basic education (2\%). The average age of the study group was 61.7 years old $(\mathrm{SD}=13.5 ; \mathrm{Me}=59)$. Respondents had taken care of their demented relative from 2-252 months (median, $\mathrm{Me}=60$ months, the most common being 35.6 months).

\section{RESULTS}

Referring to CES-D scale, the average score was $18 \pm 7.49$. The scores ranged from 7-39 points. Analysis of the results obtained in the Kolmogorov-Smirnov test of normality lets as apply parametric tests for connection allows the application of parametric tests of individual variables with the level of depression $(\mathrm{p}=.152)$.
Table 1. Demographic - situational items and level of depression

\begin{tabular}{cccc}
\hline Statistic & Age of caregiver & $\begin{array}{c}\text { Time spent with } \\
\text { person with dementia }\end{array}$ & $\begin{array}{c}\text { Satisfaction of } \\
\text { social support }\end{array}$ \\
\hline Rho & .06 & .18 \\
\hline P & .70 & .72 & .27 \\
\hline N & 37 & 39 & 41 \\
\hline
\end{tabular}

a-Pearson correlation coefficient

There was no statistically significant relationship between the level of depression and such factors as: caregiver's age, time of care of demented relative, satisfaction of with social support (Tab. 1). Similarly, the type of kinship (spouse: $n=18$, adult child: $n=12$, other: $n=11$ ) had no influence on the level of depression $(\mathrm{F}[2,38]=1.499 ; \mathrm{p}=.236)$.

It was also investigated whether support given for caregiver of demented relative was related to the level of depression. According to the estimation of received support (Support_GP) there was no statistically significant difference $(\mathrm{t}[38]=-0.94$; $\mathrm{p}=0.354$ ) between the level of depression (CES-D scale) in caregivers who received support $(\mathrm{N}=23)$ and those who did not receive support $(\mathrm{N}=18)$ (Tab.2).

Table 2. Relationship between level of depression (CES-D) and having support

\begin{tabular}{lccccc}
\hline Support & $\begin{array}{c}\text { Group } \\
\text { 'Yes' }\end{array}$ & $\begin{array}{c}\text { Group } \\
\text { 'No' }\end{array}$ & $\mathrm{t}(\mathrm{df})$ & $\mathrm{P}$ & $\begin{array}{c}95 \% \mathrm{Cl} \text { of } \\
\text { difference }\end{array}$ \\
\hline $\mathrm{GP}$ & 16.78 & 18.96 & $-0.94(38)$ & 0.354 & $-6.88,2.52$ \\
\hline Dementia Supervisor & 17.81 & 18.60 & $-0.33(20)$ & 0.745 & $-5.82,4.24$ \\
\hline Relatives and Friends & 18.56 & 17.84 & $0.26(14)$ & 0.800 & $-5.22,6.64$ \\
\hline Home services* & 17.69 & 20.20 & 84.00 & 0.826 & $-16.78,11.77$ \\
\hline Day centre* & 18.13 & 16.33 & 62.50 & 0.802 & $-11.48,15.08$ \\
\hline Selfhelp group* & 18.50 & 11.67 & 89.50 & 0.108 & $2.12,11.54$ \\
\hline Local parish* & 18.31 & 12.00 & 60.50 & 0.203 & $2.43,10.19$ \\
\hline
\end{tabular}

*-the score of nonparametrictest (Wilcoxon) because the small amount of caregivers were satisfied with received support (Home services: $n=5$, Day centre: $n=3$, Selfhelp group: $n=3$, Local parish: 2 )

Although the Table 2 shows that there was no correlation between received support and level of depression, it should be noted that there was such a small amount of caregivers who were satisfied with given support.

Pain (SF result) was another dependent variable in the study. The difference between those who felt pain $(\mathrm{N}=33)$ and those who did not feel pain $(\mathrm{N}=8)$ was not statistically significant $(\mathrm{t}[11]=0.00 ; \mathrm{p}=1.000)$. Similarly, there were no statistically significant differences between age $(t[9]=-0.08$; $\mathrm{p}=0.934)$ and the time of caregiving $(\mathrm{W}=121.50 ; \mathrm{p}=0.931)$ and the level of depression of caregivers.

Analysis of the distribution of the number of people caring for demented relatives in relation to the perceived pain showed no significant correlation between the variables $\left.\left(\mathrm{chi}^{2}\right]=4.11 ; \mathrm{p}=0.128\right)$

\section{DISCUSSION}

Caregivers play an important role in the management of individuals with dementia. Nowadays, it is well known that informal caregivers require support in order to avoid burden. Many informal caregivers may suffer from chronic health problems, for instance, depression, which should be diagnosed as early as possible, especially among family 
caregivers of ademented relative. Depressive symptoms, in turn, may increase the risk of memory loss and dementia. This is why it would be very difficult, or even impossible, to take care of a relative effectively if the caregiver develops depressive symptoms [8]. Depression is a negative prognostic indicator for hippocampal neuronal loss and cortical thinning in the prefrontal cortex. There may also be an association between depression and dementia - depression and dementia both have vascular disorders in common [9].

In addition, there are some factors that may contribute to the development of symptoms of depression, for example, sleeping problems, illness in the family and social isolation. Taking care of a demented relative is very often associated with sleep disturbance, because if a demented relative suffers from insomnia, then the caregiver is sometimes woken up at night. The appearance of a progressive and long-term illness such as dementia in a beloved parent or spouse, is also a stressful situation which may trigger the symptoms of depression. Taking care of a demented relative is connected with devotion of time and attention to the demented relative. Furthermore, a person with dementia has problem with consciousness and communication; it is sometimes difficult to talk with her or him and have even an ordinary conversation. This exaggerates the feeling of sadness and loneliness. Progression of the disease, which is inevitable, may lead to loss of motivation to take care of the demented person.

The study also checked whether there were any additional factors which may increase the risk of depression, as advanced age may be related with the appearance a depression [10]. This was the reason for checking whether age was related to symptoms of depression. Similarly to the presented study, there is research which shows that depression remains constant with increasing age [11].

Motivation to take care of a demented relative is probable such a strong factor which bonded the family together so that advanced age does not play any role in the appearance of depression. Even if a caregiver presents the symptoms of depression, his or her disease would not change the time of caregiving. Similarly, progression of the patient's disease dementia, had no impact on the clinical characteristics of the caregivers [12]. The condition of the caregiver seems to be more an outcome of the actions and activities taken rather than the time devoted [13].

It seems obvious that adequate support of caregivers is an indispensable part of any dementia care management. Psychosocial interventions should assist both demented patients and their relative in order to optimize dementia care. Comprehensive individualized care should consist of physical, psychological and social issues of both the persons with dementia and the caregiver. The general practitioner should also available in order to make regular reviews of people with dementia and their caregivers [14]. Having a respite in caregiving may have a good influence on both the physical condition and mood of caregivers and their demented relative [15]. This, however, is not the most important factor in decreasing the feelings associated with depression. Even if the caregiver has support in taking care of a demented relative, for instance, the general practitioner, home services, self-help group or local parish, it does not change the level of depression. This should be carefully considered, because the reason for respite services not decreasing the level of depression, may lie perhaps in the lack of integration and coordination of their work, or in the small study group [15].
Informal caregiver should know that they are at risk not only in reduced physical health, but also in their mental condition. Consequently, their quality of life may decreased. Having a family member with a chronic illness is associated with some spillover effects which may vary by the type of relationship with the ill family member [16]. There occur such feelings in caregiving as guilt, worry and depression; higher levels of guilt are associated with higher levels of depression. Higher levels of guilt among family member of demented relative, especially of a daughter, are related to a lower level of leisure activities [17]. Another spillover effect of caregiving associated with mental health, is feeling worried. In general, this is a significant predictor of sanity, especially in daughters. However, wives feel worried the most, while husbands worry the least [18]. Adult daughters, wives and husbands had comparable caregiver burden scores, but adult daughters had greater caregiver burden scores, compared to more distant relatives [19].

Some researchers have revealed that, similar to the presented study, there is no statistically significant difference between the different types of relationships and caregiver burden [20]. Similarly, the type of relationship to the demented person does not seem to differ the level of depression. Although there was no statistical significant correlation between the level of depression and type of kinship, the problem with quality of life, worries and grief which may appear, seem to be sufficient reason for organize psycho-education for all informal caregivers of persons with dementia. Psychoeducational group programmes may decrease behaviour problems in members of families with relatives with dementia [21]. The psychoeducatiinal group may play a significant role in reducing the stress, tension and spillover of caring for a demented relative. It can also be a support, and broaden the knowledge about dementia, which may also have a positive influence on the family of the demented person.

It is obvious that pain may accompany serious illness: both the person suffering from dementia and those who take care of relative with a prolonged, serious illness. Pain is also associated with caregiver burden [22]. However, the pain may have few different meanings; for example, if a person can stand the pain, she or he may feel stronger, thereby increasing self-esteem, and depression will not even appear [21]. Perhaps this explains why there was no statistical significant correlation between pain and level of depression in this study [23]. However, many persons with dementia and their caregivers report physical, psychological, and dementiaspecific symptoms, such as pain and depression at the same time [24].

\section{CONCLUSIONS}

The aim of national governments should be cope with the symptoms of depression, or even prevent the appearance of any symptoms of depression, especially in informal caregivers of demented persons. An illness such as depression leads to the exclusion of the sufferer from society, and is associated with additional costs for the State. Perhaps it would be worthwhile assigning a nurse and psychologist in order to help caregivers to identify their negative feelings and experiences about caregiving. It may help them reflect upon the coping strategies to find a balance in their situation [25]. 
Although there is no relationship between the level of depression and demographic features, the problem with quality of life, worries and grief which may appear, seem to be sufficient reason to organize the prevention of depression for all of informal caregivers of persons with dementia.

\section{Acknowledgements}

The study was financed by European Union Grant No. AAL $5 / 1 / 2013$, and a Grant from UnderstAid - a project that helps informal caregivers to understand and assist their demented relatives (Agreement No. AAL 5/1/2013 - The National Centre for Research and Development Director Decision No. 44/2013 of 20 February 2013). The funding bodies were not involved in the study design, collection of information, analysis and interpretation of data, the writing of the manuscript, or in the decision to submit the manuscript for publication [26].

The article written as part of the research grant: UnderstAID - a platform that help informal caregivers to understand and aid their demented relatives.

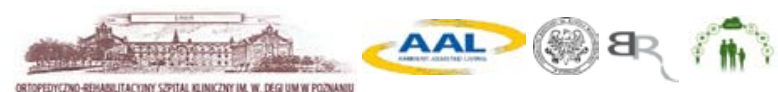

\section{REFERENCES}

1. Kang HS, Myung W, Na DL, Kim SY, Lee JH, Han SH, Choi SH, Kim SY, Kim S, Kim DK. Factors Associated with Caregiver Burden in Patients with Alzheimer's Disease. Psychiatry Investig. 2014; 11(2): 152-15.

2. Al-Qazzaz NK, Ali SH, Ahmad SA, Chellappan K, Islam MS, Escudero J. Role of EEG as Biomarker in the Early Detection and Classification of Dementia. ScientificWorldJournal. 2014; 2014: 906038.Published online Jun 30, 2014. 10.1155/2014/906038

3. Razani J, Corona R, Quilici J, Matevosyan AA, Funes C, Larco AA, Miloyan B, Avila J, Chung J, Goldberg H, Lu P. The Effects of Declining Functional Abilities in Dementia Patients and Increases Psychological Distress on Caregiver Burden Over a One-Year Period. Clin Gerontol. 2014; 37(3): 235-252.

4. Allegri RF, Sarasola D, Serrano C,Taragano FE, Arizaga FL, Butman J, Lon L.Neuropsychiatric symptoms as a predictor of caregiver burden in Alzheimer's disease. Neuropsychiatr Dis Treat. Mar 2006; 2(1): 105-110.

5. Katona C, Peveler R, DowrickCh, Wessely S, FeinmannCh, Gask L, Lloyd H, Williams ACC, Wager E. Pain symptoms in depression: definition and clinical significance. Clin Med. 2005;5:390-395.

6. Lan Guo L, Deng J, He Y, Deng X, Huang J, Huang G, Gao X, Lu C. Prevalence and correlates of sleep disturbance and depressive symptoms among Chinese adolescents: a cross-sectional survey study. BMJ Open. 2014; 4: e005517 doi:10.1136/bmjopen-2014-005517.

7. Marcus M, Yasamy MT, Ommeren M, Chisholm D, Saxena Sh. Depression A Global Public Health Concern Developed. WHO Department of Mental Health and Substance Abuse.http://www.who. int/mental_health/management/depression/who_paper_depression_ wfmh_2012.pdf (access: 16.08.2014).

8. Zahodne LB, Stern Y, Manly JJ. Depressive Symptoms Precede Memory Decline, but Not Vice Versa, in Non-Demented Older Adults. J Am Geriat Soc. 2014; 62(1): 130 -134.

9. Puto G, Ocetkiewicz T, Zawisza K.Wpływ depresji i funkcji poznawczych na subiektywną ocenę jakości życia pacjentów z chorobą niedokrwienną serca po 80. roku życia. Influence of depression and cognitive function on subjective assessment of quality of life in patients over 80 years old with myocardial ischemia. Gerontol Pol. 2003; 15(3): 90-96.
10. Weiss Wiesel TR, Nelson CJ, Tew WP, Hardt M, Mohile SG, Owusu C, Klepin HD, Gross CP, Gajra A, Lichtman SM, Ramani R, Katheria V, Zavala L, Hurria A. On behalf of the Cancer Aging Research Group (CARG). The relationship between age, anxiety, and depression in older adults with cancer. Psychooncology. 2014; 6. doi: 10.1002/pon.3638.

11. Ornstein K, Gaugler JE, Zahodne L, Stern Y. The heterogeneous course of depressive symptoms for the dementia caregiver. Int J Aging Hum Dev. 2014; 78(2): 133-48.

12. Brown LJ, Bond MJ. Transition from the spouse dementia caregiver role: A change for the better? Dementia (London). 2014 Jun 16. pii: 1471301214539337. [Epub ahead of print].

13. Strivens E, Craig D. Managing dementia-related cognitive decline in patients and their caregivers. Aust Fam Physician. 2014 Apr; 43(4): $170-4$.

14. Eichler T, Thyrian JR, Dreier A, Wucherer D, Köhler L, Fiß T, Böwing G, Michalowsky B, Hoffmann W. Dementia care management: going new ways in ambulant dementia care within a GP-based randomized controlled intervention trial. Int Psychogeriatr. 2014; 26(2): 247-56. doi: 10.1017/S1041610213001786. Epub 2013 Oct 23.

15. Prosser LA, Lamarand K, Gebremariam A, Wittenberg E. Measuring Family HRQoL Spillover Effects Using Direct Health Utility Assessment. Med Decis Making XXXX;XX:XX-XX. PUBLISHED 23 July 2014.DOI: 10.1177/0272989X14541328.

16. Romero-Moreno R, Losada A, Marquez M, Laidlaw K, FernándezFernández V, Nogales-González C, López J. Leisure, gender, and kinship in dementia caregiving: psychological vulnerability of caregiving daughters with feelings of guilt. J Gerontol B Psychol Sci Soc Sci. 2014; 69(4): 502-13.

17. Sparks MB, Farran CJ, Donner E, Keane-Hagerty ESch Inq Nurs Pract. Wives, husbands, and daughters of dementia patients: predictors of caregivers' mental and physical health. 1998; 12(3): 221-234; discussion 235-238.

18. Chumbler NR, Grimm JW, Cody M, Beck C. Gender, kinship and caregiver burden: the case of community-dwelling memory impaired seniors. Int J Geriatr Psychiatry. 2003; 18(8): 722-32.

19. Riedijk SR, De Vugt ME, Duivenvoorden HJ, Niermeijer MF, Van Swieten JC, Verhey HRJ, Tibben A. Caregiver Burden, Health-Related Quality of Life and Coping in Dementia Caregivers: A Comparison of Frontotemporal Dementia and Alzheimer's Disease. Dement Geriatr Cogn Disord. 2006; 22(5-6): 405-412.

20. Hébert R, Lévesque L, Vézina J, Lavoie JP, Ducharme F, Gendron C, Préville M, Voyer L, Dubois MFJ. Efficacy of a psychoeducative group program for caregivers of demented persons living at home: a randomized controlled trial. Gerontol B Psychol Sci Soc Sci. 2003; 58(1): S58-67.

21. Perrin PB, Morgan M, Aretouli E, Sutter M, Snipes DJ, Hoyos GR, Buraye JA, Arango-Lasprilla JC. Connecting health-related quality of life and mental health in dementia caregivers from Colombia, South America. J Alzheimers Dis. 2014; 39(3): 499-509.

22. Kuo LM, Huang HL, Huang HL, Liang J, Chiu YC, Chen ST, Kwok YT, Hsu WC, Shyu YI. A home-based training program improves Taiwanese family caregivers' quality of life and decreases their risk for depression: a randomized controlled trial. Int J Geriatr Psychiatry. 2013 May; 28(5): 504-13.

23. Murray TM, Sachs GA, Stocking C, Shega JW. The symptom experience of community-dwelling persons with dementia: self and caregiver report and comparison with standardized symptom assessment measures. Am J Geriatr Psychiatry. 2012; 20(4): 298-305.

24. Andrén S, Elmståhl S. The relationship between caregiver burden, caregivers' perceived health and their sense of coherence in caring for elders with dementia. J Clin Nurs. 2008; 17(6): 790-9.

25. Reinhard SC, Given B, Petlick NH, Bemis A. Supporting Family Caregivers in Providing Care. Patient Safety and Quality: An EvidenceBased Handbook for Nurses. Agency for Healthcare Research and Quality (US); Rockville 2008.

26. Warchol Biedermann K, Mojs E, Gregersen R, Maibom K, José C, Millán-Calenti JC, Maseda A. What causes grief in dementia caregivers? Archiv Gerontol Geriatr. 2014; 59: 462-467. 